\title{
Testing price-fixing agreements in a multimarket context: The European case of vitamin $\mathrm{C}$
}

\author{
Jacint Balaguer ${ }^{\mathrm{a}, *}$, Vicente Orts ${ }^{\mathrm{a}}$, Ezequiel Uriel ${ }^{\mathrm{b}}$ \\ a Department of Economics, Universitat Jaume I, Spain \\ ${ }^{\mathrm{b}}$ Instituto Valenciano de Investigaciones Económicas (IVIE) and Universitat de València, Spain
}

\begin{abstract}
In this paper, we suggest a method to test price-fixing agreements. Prices fixed to multiple shipments are decomposed into a set of destination market effects and time effects in order to allow us to perform an analysis of residuals. We examine the pricing behavior of vitamin $\mathrm{C}$ in the European destination markets of German exports. We explore two different periods: January 1991-August 1995 and September 1995-September 2001. Empirical results on the first period, which are consistent with our knowledge obtained from firms' confessions about illegal agreements, contrast notably with those obtained on the more recent period.

(c) 2007 Elsevier Inc. All rights reserved.
\end{abstract}

JEL classification: D43; L12; L41; L65

Keywords: Collusion; International markets; Vitamin C

\section{Introduction}

Unfortunately, price-fixing agreements are a frequent feature in oligopolistic market structures. This is not surprising because they can yield considerable profits for participating firms and because there is no straightforward way they can be identified by antitrust agencies. Social welfare is likely to suffer notable losses in cases which involve elements like the importance of the product for consumers, the large size of the geographic markets where participants operate, or maintaining illegal practices over a number of years.

\footnotetext{
* Corresponding author at: Department of Economics, Universitat Jaume I, 12071 Castelló, Spain.

E-mail address: Jacint.Balaguer@eco.uji.es (J. Balaguer).
} 
Although antitrust agencies can often detect illegal practices through leniency applications or dawn raids, sometimes the identification of infringements, as well as the extent of the problem generated, becomes a complicated affair. In this paper, we provide a methodology that helps to identify the presence of non-competitive pricing behavior in a simple fashion. In practice, it can be more useful in effect-based investigation. Thus, results obtained from our proposed method can assist firms in their defense or, alternatively, can constitute proof to be taken into consideration by antitrust agencies. Since analysis will be based on both the time period and the markets where firms operate, it can also be relevant to evaluate the gauge impact of price-fixing agreements.

There are at least two interesting implications that characterize the proposed approach. First, only a dataset of product prices fixed to several destination markets will be necessary, which implies that the methodology has a low cost. Second, since the methodology is based on a multimarket model, the analysis is expected to be useful for application to certain contexts where illegal agreements on prices are more likely. This idea is supported by recent studies, which show that firms' contact in multiple markets may enhance abilities to collude (Gupta, 2001; Parker \& Röller, 1997).

Our intention is to use the European case of vitamins to illustrate the method proposed here. More specifically, a dataset regarding prices fixed by German exporters of vitamin $\mathrm{C}$ over the admitted period of collusion will allow us to determine whether the empirical approach is valid to help identify price-fixing agreements. We also used the suggested methodology to investigate pricing behavior after this period. In this way, we tested whether authorities' control over the later period, with regard to the defense of competition, had been successful.

The rest of this paper is organized as follows. Section 2 develops an economic framework and discusses the implications of different market structures. In Section 3, we put forward the econometric specification and present the implications of a framework of price collusion and for two alternative market structures. In Section 4, we explore the approach using export data on vitamin $\mathrm{C}$ for the European market. The two different periods are examined using month-to-month data. The first covers the period January 1991-August 1995, where collusion is admitted by firms, and the second involves the period September 1995-September 2001, where no price coordination is expected. The final section provides the summary conclusions.

\section{The economic approximation}

The economic framework used in this paper is focused on a profit-maximizing firm behavior that produces homogeneous goods for sale in $N$ separate destination markets, which are indexed by $i$. First order conditions for profit maximization could be described by prices (in terms of $f o b)$ obtained as the product of the marginal cost $\left(\mathrm{MC}_{t}\right)$ and a mark-up $\left(\phi_{i t}\right)$, as follows:

$$
p_{i t}=\mathrm{MC}_{t}\left(\sum_{i}^{N} q_{i t}, w_{t}\right) \phi_{i t}, \quad \forall i
$$


where $t=1, \ldots, T$ index time. The marginal cost $\mathrm{MC}_{t}$, which is common to the $N$ destination markets, is a function of the level of total production of the firm $\sum_{i}^{N} q_{i t}$, and the input price $w_{t}$.

Assuming that destination-specific mark-up could depend on price competitiveness, we can define it as the relative price in local market terms (Hung, Kim, \& Ohno, 1993; Kongsted, 1998). In this way, an approximation of the optimal price, where arguments of $\mathrm{MC}_{t}$ have been removed, can be written (in logs) as:

$$
\ln p_{i t}=\ln \mathrm{MC}_{t}+\ln \kappa_{i}+\beta \ln \left(\frac{p_{i t}^{\mathrm{c}}}{p_{i t} f_{i}}\right)+\varepsilon_{i t}
$$

where $\kappa_{i}$ is a constant term of mark-up over marginal cost which is specific to market $i, p_{i t}^{\mathrm{c}}$ the index of prices of local competitors (in terms of cif) and $f_{i}$ represents the specific iceberg cost of shipping consumer goods to destination $i$. Thus, $\left(p_{i t}^{\mathrm{c}} / p_{i t} f_{i}\right)=P_{i t}$ is the relative price in local market $i$. The coefficient $\beta$ should be interpreted as the relative price elasticity of the mark-up $(\beta>0)$. Lastly, $\varepsilon_{i t}$ is a stochastic variable which is independent, identically and normally distributed with mean zero and variance $\sigma_{\varepsilon}^{2}$.

The involvement of the different market structures in non-random components in Eq. (2) is straightforward. Let us consider the single competitive market, where $p_{i t}^{\mathrm{c}}=p_{i t} f_{i}$. The fulfillment of this hypothesis requires prices to be equal to marginal cost, which is common across destination markets and implies $\ln \kappa_{i}=\beta \ln (1)=0$.

An alternative hypothesis is the presence of collusive prices. Although this hypothesis also implies price parallelism between firms within each destination market, in this case the relative price can take a value other than one. When this occurs, then $\beta \ln \left(p_{i t}^{\mathrm{c}} / p_{i t} f_{i}\right)=$ $\beta \ln \left(P_{i}\right) \neq 0$. Furthermore, in this interesting case, firms' practices presumably involve third degree price discrimination as well as the segmentation of markets. Thus, the existence of mark-up differences across destinations is represented in Eq. (2) by $\ln \kappa_{i}+\beta \ln \left(P_{i}\right)$.

Lastly, changes in the relative price are inconsistent with both hypotheses (perfect competition and price collusion). This phenomenon is consistent with an extensive range of imperfect competition market structures in which the degree of competition is directly related to the value of the relative price elasticity $\beta$. In this range of cases, firms take into account changes in relative prices. Since the optimal price becomes an endogenous variable, the total effect is obtained by:

$$
\ln p_{i t}=\gamma \ln \mathrm{MC}_{t}+\gamma \ln k_{i}+(1-\gamma) f_{i}+(1-\gamma) \ln p_{i t}^{\mathrm{c}}+\gamma \varepsilon_{i t}
$$

where $\gamma=1 /(1+\beta)$. Eq. (3) shows that while $\beta$ is large (or $\gamma$ is low), the firm follows competitors' prices and the market is characterized by a high degree of competition. The next section presents a simplification of Eq. (3) that will be capable of distinguishing between the market structure in which we are interested and a range of intermediate market structures and the perfect competition case.

\section{Research design}

This section centers on the research design used to test collusion and its empirical implications in a simple fashion. Our research design is based on a decomposition of prices $p_{i t}$, 
where explanatory variables of Eq. (3) are taken to be unobservable. Differences between the closely related markets will allow us to trace the effects of the idiosyncratic characteristics of destination markets and common changes (like marginal cost, which is in accordance with the central ideas of the "new empirical industrial organization" studies, surveyed in Bresnahan, 1989). Since we take the relative price to be an unobservable variable, statistical information requirements are low and the methodology involves a notable degree of pragmatism. It is obvious that sometimes a scarcity of data at firm level makes it difficult to build an accurate index of competitors' prices for each of the destination markets.

Price decomposition could be represented as a fixed-effects regression model, as follows:

$$
\ln p_{i t}=\alpha+\theta_{t}+\lambda_{i}+v_{i t}
$$

where $\alpha$ is a constant term, $\theta_{t}$ the coefficients of the time effects which capture any common movements in prices over time across all destination markets (and, obviously, excludes $\theta_{1}$ to avoid collinearity with the constant term), and $\lambda_{i}$ is a set of market effects (that excludes $\left.\lambda_{1}\right)$. The last term, $v_{i t}$, is an error term. The implication of the coefficients from Eq. (4) in the diverse market structures could be illustrated by the economic framework described in the previous section.

First, the fulfillment of the perfect competition hypothesis implies that firm prices are fully explained by the constant term and the set of time effects. Thus, $\lambda_{i}$ is zero for overall destination markets and the regression disturbance $\left(v_{i t}\right)$ equals $\varepsilon_{i t}$. In this case, while the constant $\alpha$ captures the marginal cost that corresponds to the first period $\left(\mathrm{MC}_{1}\right)$, the time effects $\theta_{t}$ will measure their evolution $\left(\mathrm{MC}_{t}, t=2, \ldots, T\right)$. This evolution equals the common changes in price in each period.

Second, the fulfillment of the hypothesis concerning non-competitive segmented markets, where pricing behavior depends on the idiosyncratic demand schedule faced by the firm inside each market, requires $\lambda_{i}$ to have a value other than zero. While $\theta_{t}$ captures both the evolution of common mark-up and marginal cost, $\lambda_{i}(i=2, \ldots, N)$, indicates the specific mark-up difference from the destination country indexed by $i=1$. If price coordination implies that $p_{i t}$ equals $p_{i t}^{\mathrm{c}}$, ${ }^{1}$ then $v_{i t}$ is distributed in an identical and independent manner and it is equal to $\varepsilon_{i t}$.

In the alternative market structures relative prices come into play. Therefore, the constant term, and the fixed effects from Eq. (4) are insufficient to explain pricing behavior. In this case, the error term $\left(v_{i t}\right)$ captures both a random factor and a deterministic factor. More specifically, it captures $\gamma \varepsilon_{i t}+(1-\gamma) \ln p_{i t}^{\mathrm{c}}$, where $\gamma$ acts as the coefficient for the linear combination of the random and a deterministic factor.

\section{The case of vitamin $C$ : data and results}

The very well known collusion between the primary manufacturers of vitamins is a good example of the damaging effects of collusion. The participants maintained illegal practices

\footnotetext{
${ }^{1}$ In the more general case of price parallelism in each destination market, $\lambda_{i}$, could also include the constant gap between firms' prices.
} 
Table 1

Market shares of sales by vitamin types in the EU market

\begin{tabular}{lrrr}
\hline Product & 1994 & 1996 & 1998 \\
\hline Vitamin C & 27.79 & 20.84 & 15.24 \\
Vitamin E & 23.18 & 27.81 & 31.74 \\
Vitamin A & 16.97 & 18.30 & 18.98 \\
Beta carotene & 6.81 & 8.45 & 9.83 \\
Canthaxanthin & 6.01 & 6.34 & 6.45 \\
Vitamin B2 & 5.06 & 4.88 & 4.36 \\
Biotin (H) & 4.32 & 3.96 & 2.98 \\
Pantothenates/calpan (B5) & 3.83 & 4.08 & 4.51 \\
Vitamin B1 & 2.18 & 1.58 & 1.91 \\
Vitamin D3 & 1.98 & 2.54 & 2.61 \\
Vitamin B6 & 1.87 & 1.21 & 1.39 \\
\hline
\end{tabular}

Source: Percentages calculated from data published in the Official Journal of the European Communities $(10 / 1 / 2003)$.

over a number of years and operated over a large area of the geographic markets. This is the reason why, at the end of 2001, the European Commission imposed record fines on eight pharmaceutical companies (bearing in mind that an important part of the agreement took place within the European economic area). ${ }^{2}$ The special consideration of the case can be derived from the following statement made by the member of the European Commission responsible for competition, Mario Monti:

"This is the most damaging series of cartels the Commission has ever investigated due to the sheer range of vitamins covered which are found in a multitude of products from cereals, biscuits and drinks to animal feed, pharmaceuticals and cosmetics ... The companies' collusive behavior enabled them to charge higher prices than if the full forces of competition had been at play, damaging consumers and allowing the companies to pocket illicit profits. It is particularly unacceptable that this illegal behavior concerned substances which are vital elements for nutrition and essential for normal growth and maintenance of life." (November 2001)

In this case, some participants cooperated with the European Commission ${ }^{3}$ and admitted the existence of cartel agreements quite early on, thus facilitating the investigation, after being encouraged by the possibility of obtaining a substantial reduction in the fines that would eventually be imposed.

Since the period of time in which price agreements were maintained by the firms involved is well defined, we use data about the vitamin industry to illustrate the empirical method in a straightforward manner. More specifically, we conduct a study of the European market pricing behavior of vitamin $\mathrm{C}$, which is together with vitamins $\mathrm{A}$ and $\mathrm{E}$ one of most important products sold by drug firms (Table 1). A first stage of the analysis is based on OLS estima-

\footnotetext{
${ }^{2}$ Fines were imposed on the following companies (in order of importance): Hoffmann-La Roche (Switzerland), BASF AG (Germany), Aventis SA (France), Solvay Pharmaceuticals BV (Netherlands), Merck KgaA (Germany), Daiichi Pharmaceutical Co. Ltd. (Japan), Esai Co. Ltd. (Japan) and Takeda Chemical Industries Ltd. (Japan).

3 Since price agreements took place in other important markets like USA, participants also cooperated with the United States Department of Justice.
} 




Fig. 1. Estimated time effects for the two periods.

tion from Eq. (4). To do so, we use unit values as a proxy variable of export prices of the vitamin. Unit value indices are calculated from data collected from the COMEXT database (published by Eurostat). ${ }^{4}$ We have chosen to study the value indices obtained from German exports, which will represent the price dynamics of two of the four firms involved in the illegal agreements (BASF AG and Merck KgaA). ${ }^{5}$ Furthermore, German shipments provide a steady, important volume of vitamin exports to several destination markets on a monthly basis. The study focuses on the main destination markets of German vitamin $\mathrm{C}$ exports in the European Union. In particular, we will obtain specific results for France, Belgium and Luxembourg, Netherlands, Italy, United Kingdom, Spain and Austria. The export data covers both the whole period of successful collusion in the European market, following the information offered by the Official Journal of the European Communities (Commission Decision of November 21, 2001, Case COMP/E-1/37.512), ${ }^{6}$ that is to say, January 1991-August $1995^{7}$ and a more recent period between September 1995 and September 2001. From the results obtained by the investigation carried out by the Commission, we

\footnotetext{
${ }^{4}$ Database follows the Integrated Tariff of the European Communities classification. Vitamin C is classified with code number 293627.

5 The remaining firms involved in the vitamin C agreements belong to Switzerland (Hoffmann-La Roche) and Japan (Takeda Chemical Industries Ltd.).

${ }^{6}$ As the Official Journal indicates, the importance and the duration of the agreements is not necessarily the same for all participants and destination countries.

${ }^{7}$ German firms are subjected to frequent variations in the exchange rates in destination markets of exports throughout of this period, which automatically induces changes in competitiveness. Thus, without the existence of price agreements, the relative prices would change regularly following the models based on the pricing-to-market behavior (Dornbusch, 1987; Krugman, 1987).
} 
Table 2

White noise test for residuals based on the Box-Pierce statistic for the period from January 1991 to August 1995

Destination country $(i) \quad$ Lags $(L)$

\begin{tabular}{|c|c|c|c|c|c|c|c|c|c|c|}
\hline & 1 & 2 & 3 & 4 & 5 & 6 & 7 & 8 & 9 & 10 \\
\hline rance & $0.085(0.926)$ & $0.721(0.697)$ & $0.915(0.822)$ & $3.288(0.511)$ & $5.322(0.378)$ & $5.442(0.489)$ & $7.705(0.359)$ & $7.762(0.457)$ & $7.811(0.553)$ & 7.854 (0.643) \\
\hline Belgium-Luxembourg & $2.894(0.089)$ & $9.946(0.007)$ & 13.594 (0.004) & $14.374(0.006)$ & $14.774(0.011)$ & $16.529(0.011)$ & $17.108(0.017)$ & $18.379(0.019)$ & $23.475(0.005)$ & $25.529(0.004)$ \\
\hline Tetherlands & $3.270(0.071)$ & $3.3505(0.187)$ & $3.406(0.333)$ & $3.464(0.483)$ & $3.615(0.606)$ & $3.625(0.727)$ & $4.771(0.688)$ & $5.506(0.702)$ & $5.537(0.785)$ & $6.086(0.808)$ \\
\hline aly & $0.825(0.364)$ & $0.982(0.612)$ & $0.988(0.804)$ & $1.600(\mathrm{C}$ & 2.147 & 3.114 & 3.120 & 3.142 & 3.772 & $4.751(0.907)$ \\
\hline United Kingdom & $5.496(0.019)$ & $5.506(0.064)$ & $5.720(0.126)$ & $6.918(0.140)$ & $9.273(0.159)$ & $8.583(0.198)$ & $8.583(0.284)$ & $9.684(0.288)$ & $9.782(0.368)$ & $15.013(0.136)$ \\
\hline Spain & $0.224(0.636)$ & $3.811(0.149)$ & $4.239(0.237)$ & $4.300(0.367)$ & $5.758(0.330)$ & $5.760(0.451)$ & $6.495(0.483)$ & $6.542(0.587)$ & $12.740(0.175)$ & $15.976(0.101)$ \\
\hline Austria & $0.098(0.753)$ & $0.484(0.785)$ & $2.790(0.425)$ & $3.766(0.439)$ & $8.767(0.119)$ & $9.032(0.172)$ & $9.750(0.203)$ & $10.062(0.261)$ & $10.926(0.281)$ & $11.528(0.318)$ \\
\hline
\end{tabular}

Note: Statistic is distributed as the chi-squared with $L$ degrees of freedom. Values in brackets correspond to significance levels. Results were obtained with $L i m d e p ~ 7.0$. 
Table 3

White noise test for residuals based on the Box-Ljung statistic for the period from January 1991 to August 1995

\begin{tabular}{|c|c|c|c|c|c|c|c|c|c|c|}
\hline \multirow[t]{2}{*}{ Destination country $(i)$} & \multicolumn{10}{|l|}{ Lags $(L)$} \\
\hline & 1 & 2 & 3 & 4 & 5 & 6 & 7 & 8 & 9 & 10 \\
\hline France & $0.009(0.924)$ & $0.774(0.679)$ & $0.986(0.805)$ & $3.634(0.458)$ & $5.946(0.311)$ & $6.085(0.414)$ & $8.765(0.270)$ & $8.833(0.356)$ & $8.894(0.447)$ & $8.948(0.537)$ \\
\hline Belgium-Luxembourg & $3.052(0.081)$ & $10.626(0.005)$ & $14.619(0.002)$ & $15.488(0.004)$ & $15.943(0.007)$ & $17.979(0.006)$ & $18.665(0.009)$ & $20.201(0.010)$ & $26.488(0.002)$ & $29.079(0.001)$ \\
\hline Netherlands & $3.448(0.063)$ & $3.535(0.171)$ & $3.595(0.309)$ & $3.660(0.454)$ & $3.832(0.574)$ & $3.843(0.698)$ & $5.200(0.636)$ & $6.089(0.637)$ & $6.126(0.727)$ & $6.818(0.743)$ \\
\hline Italy & $0.871(0.351)$ & $1.039(0.595)$ & $1.045(0.790)$ & $1.718(0.786)$ & $2.351(0.799)$ & $3.472(0.748)$ & $3.479(0.838)$ & $3.505(0.899)$ & $4.283(0.892)$ & $5.517(0.854)$ \\
\hline United Kingdom & $5.795(0.016)$ & $5.807(0.054)$ & $6.040(0.110)$ & $7.496(0.117)$ & $9.106(0.105)$ & $9.273(0.159)$ & $9.274(0.234)$ & $10.605(0.225)$ & $10.725(0.295)$ & $17.321(0.068)$ \\
\hline Spain & $2.236(0.627)$ & $4.089(0.129)$ & $4.558(0.207)$ & $4.626(0.328)$ & $6.284(0.280)$ & $6.286(0.392)$ & $7.155(0.413)$ & $7.212(0.514)$ & $14.861(0.095)$ & $18.931(0.041)$ \\
\hline Austria & $0.104(0.741)$ & $0.518(0.772)$ & $3.041(0.385)$ & $4.131(0.389)$ & $9.817(0.081)$ & $10.125(0.120)$ & $10.975(0.140)$ & $11.352(0.183)$ & $12.418(0.191)$ & $13.178(0.214)$ \\
\hline
\end{tabular}

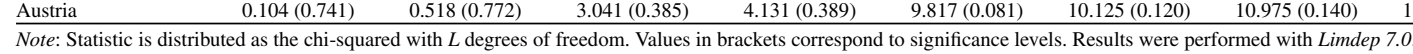


Table 4

Estimates of constant term and country-fixed effects for the period from January 1991 to August 1995

\begin{tabular}{lc}
\hline Constant and destination country effect $(i)$ & Coefficient $(P$-value $)$ \\
\hline$\alpha$ & $2.341(0.000)$ \\
$\lambda_{\text {Belgium-Luxembourg }}$ & $0.013(0.388)$ \\
$\lambda_{\text {Netherlands }}$ & $0.013(0.371)$ \\
$\lambda_{\text {Italy }}$ & $-0.055(0.000)$ \\
$\lambda_{\text {United Kingdom }}$ & $-0.012(0.407)$ \\
$\lambda_{\text {Spain }}$ & $-0.535(0.000)$ \\
$\lambda_{\text {Austria }}$ & $0.022(0.142)$ \\
\hline
\end{tabular}

Note: The reference group is France. A positive coefficient means that export prices are on average more expensive than the reference group. The $t$-statistics, which are in brackets, are robust to heteroscedasticity. The estimates were performed with Limdep 7.0.

expect the illegal agreements to have been finished in this later period. ${ }^{8}$ We will thus be able to compare results for the two periods.

Estimated time effects are represented in Fig. 1. We can observe that the common price evolution of vitamin $\mathrm{C}$ differs clearly between the two periods. While the common component of prices was quite stable over the collusion period, it decreased dramatically during the first two years of the later period. This finding appears as an immediate consequence of ending the agreements on vitamin $\mathrm{C}$.

In a second stage, we studied the residuals of regression for both periods with the intention of discovering whether a deterministic component is included. If such a deterministic component is revealed, then collusion and a perfect competitive market would be rejected. Otherwise, the presence of idiosyncratic mark-up according to destination can separate these last two alternatives.

Tables 2 and 3 present the analyses of residuals for the first period (January 1991-August 1995) based on the Box-Pierce statistic (Box \& Pierce, 1970) and the Box-Ljung statistic (Ljung \& Box, 1979), respectively. We explored the statistical results with a set of degrees of freedom $(L=1,2, \ldots, 10)$ for each destination country. We cannot deny that, in general, the residuals follow a white noise process. When we attempt to apply the Box-Pierce statistic, we cannot reject independence of residuals over time for 65 out of 70 cases at the $1 \%$ level. When the Box-Ljung statistic is applied, the hypothesis is not rejected in 62 out of 70 cases. The only clear exception corresponds to Belgium-Luxembourg as a destination where, in view of the results, we can conclude that illegal agreements did not take place at all during the period under consideration. Therefore, the evidence obtained is, in general, consequent with the presence of price parallelism over this period. However, a white noise process is a necessary but insufficient condition to support price coordination.

Rejection of perfect competition, in favor of non-competitive prices, is corroborated by significant differences in the estimations of country-fixed effects. As well as the product's being homogeneous, from the results included in Table 4, we can infer that there is also a

\footnotetext{
${ }^{8}$ Although the precise stage at which the agreement on vitamin $\mathrm{C}$ was withdrawn is not documented, the Commission's decision is based on this date.
} 
Table 5

White noise test for residuals based on the Box-Pierce statistic for the period from September 1995 to September 2001

\begin{tabular}{|c|c|c|c|c|c|c|c|c|c|c|}
\hline \multirow[t]{2}{*}{ Destination country $(i)$} & \multicolumn{10}{|l|}{ Lags $(L)$} \\
\hline & 1 & 2 & 3 & 4 & 5 & 6 & 7 & 8 & 9 & 10 \\
\hline France & $30.801(0.000)$ & $48.479(0.000)$ & $64.413(0.000)$ & $79.405(0.000)$ & $90.940(0.000)$ & $101.989(0.000)$ & $112.450(0.000)$ & $121.859(0.000)$ & $132.291(0.000)$ & $141.840(0.000)$ \\
\hline Belgium-Luxembourg & $22.255(0.000)$ & $32.385(0.000)$ & $34.822(0.000)$ & $35.780(0.000)$ & $38.170(0.000)$ & $41.164(0.000)$ & $46.240(0.000)$ & $46.968(0.000)$ & $48.017(0.000)$ & $48.375(0.000)$ \\
\hline Netherlands & $32.591(0.000)$ & $65.320(0.000)$ & $94.424(0.000)$ & $123.863(0.000)$ & $152.575(0.000)$ & $175.166(0.000)$ & $199.529(0.000)$ & $216.480(0.000)$ & $235.786(0.000)$ & $249.430(0.000)$ \\
\hline United Kingdom & $5.886(0.015)$ & $11.145(0.004)$ & $14.5630 .002)$ & $22.111(0.000)$ & $36.496(0.000)$ & $32.529(0.000)$ & $40.485(0.000)$ & $42.614(0.000)$ & $48.452(0.000)$ & $53.781(0.000)$ \\
\hline Spain & $35.856(0.000)$ & $63.042(0.000)$ & $79.222(0.000)$ & $94.405(0.000)$ & $111.519(0.000)$ & $130.025(0.000)$ & $147.767(0.000)$ & $159.817(0.000)$ & $48.452(0.000)$ & $170.792(0.000)$ \\
\hline Austria & $5.491(0.019)$ & $11.399(0.003)$ & $18.297(0.000)$ & $24.722(0.000)$ & $35.486(0.000)$ & $41.588(0.000)$ & $50.378(0.000)$ & $52.825(0.000)$ & $57.597(0.000)$ & $60.642(0.000)$ \\
\hline
\end{tabular}

Note: Statistic is distributed as the chi-squared with $L$ degrees of freedom. Values in brackets correspond to significance levels. Results were performed with Limdep 7.0 
Table 6

White noise test for residuals based on the Box-Ljung statistic for the period from September 1995 to September 2001

Destination country $(i) \quad$ Lags $(L)$

\begin{tabular}{|c|c|c|c|c|c|c|c|c|c|c|}
\hline & 1 & 2 & 3 & 4 & 5 & 6 & 7 & 8 & 9 & 10 \\
\hline rance & $2.084(0.000)$ & $50.758(0.000)$ & $67.830(0.000)$ & $84.126(0.000)$ & $99.848(0.000)$ & $109.217(0.000)$ & $121.105(0.000)$ & $131.961(0.000)$ & $144.186(0.000)$ & $155.554(0.000)$ \\
\hline lgium & $182(0.000)$ & $.883(0.000)$ & $36.494(0.000)$ & $.557(0.000)$ & $40.171(0.000)$ & $43.523(0.000)$ & 49.291 & 50.131 & $51.360(0.000)$ & $51.787(0.000)$ \\
\hline Netherlands & $.949(0.000)$ & $3.522(0.000)$ & $99.705(0.000)$ & $131.704(0.000)$ & $163.372(0.000)$ & $188.660(0.000)$ & $216.344(0.000)$ & $235.904(0.000)$ & $258.528(0.000)$ & $274.771(0.000)$ \\
\hline Italy & $18.028(0.000)$ & $36.724(0.000)$ & $55.670(0.000)$ & $79.398(0.000)$ & $93.216(0.000)$ & $103.074(0.000)$ & $118.177(0.000)$ & $133.082(0.000)$ & $142.094(0.000)$ & $145.133(0.000)$ \\
\hline ited $\mathrm{K}$ & 3) & $11.687(0$ & $490.001)$ & & 39.484 & 00) & $4(0.000)$ & 00) & 00) & $59.659(0.000)$ \\
\hline & )) & sor & & & & 139. & & & & $186.527(0.000)$ \\
\hline Austria & $5.720(0.017)$ & $11.961(0.002)$ & $19.351(0.000)$ & $26.335(0.000)$ & $57.850(0.000)$ & $38.207(0.000)$ & $55.026(0.000)$ & $57.850(0.000)$ & $63.442(0.000)$ & $67.067(0.000)$ \\
\hline
\end{tabular}

Note: Statistic is distributed as the chi-squared with $L$ degrees of freedom. Values in brackets correspond to significance levels. Results were performed with $L$ imdep 7.0 . 
constant mark-up component which depends critically on the destination country. ${ }^{9}$ That is, for example, mark-ups obtained from sales to both Spain and Italy are significantly smaller than the mark-up obtained from sales to the French market (which is the reference country in the regression). Obviously, differences in mark-ups across destinations agree with the price collusion that was proved to have existed over this period.

The residuals obtained from the most recent period were also analyzed using the values of the Box-Pierce and the Box-Ljung statistics. Tables 5 and 6 include results for these statistics, respectively. As we can see, results contrast notably with those obtained over the period of admitted price coordination. We now reject, at the $1 \%$ level, a white noise process for residuals in all destination countries in a very clear way. It can therefore be inferred that residuals capture a deterministic component and, consequently, time and destination effects are insufficient to explain the German pricing behavior. The presence of a deterministic component supports the presence of non-cooperative strategies on prices in an imperfect competition framework.

\section{Concluding remarks}

The main purpose of this paper was to provide an empirical method for identifying the presence of illegal price agreements in international markets. In practice we hope that, when cases are effect based, the approach suggested here can help regulators to investigate price collusion and, depending on individual circumstances, contribute to the defense of firms. Since it allows both the specific geographic markets and the duration of infringements to be analyzed, the methodology can be useful to evaluate the damage impact and, obviously, to calculate the basic amount of the fine.

The hypothesis of price collusion has been stated throughout our analysis. We divided the other market structures into two alternative hypotheses, namely, the perfectly competitive market hypothesis, and a wide range of market structures where there are changes in competitiveness which affect optimal prices. We suggest a simple empirical model in which each of these alternatives can be chosen with little statistical information being required. The approach is based on the estimation of a two-factor fixed-effects model and on the analysis of residuals.

The European market for vitamin $\mathrm{C}$ provides an excellent framework to illustrate the basic aspects of the empirical procedure. Here, we use a variable proxy for the German export prices over two different periods. First, a period of general agreements of price collusion is admitted by participating firms (from January 1991 to August 1995). Second, there is another later period where information reported by firms indicates that there was no price collusion (from September 1995 to September 2001). Empirical results support this information.

Outcomes obtained concerning the first period were consistent with the fulfillment of the non-competitive price hypothesis for most of the destination markets. More specifically,

\footnotetext{
${ }^{9}$ In practice, differences in country effects may result from other aspects that have not been considered. For example, country effects could show differences in product quality across destination countries which are caused by differences in tastes or per capita incomes.
} 
we found a great deal of evidence for price parallelism within international markets and discriminatory pricing across destinations. The analysis, which supports price collusion over nearly five years in at least six of the European destination markets, corroborates the importance of the harm caused to vitamin C consumers. Empirical results are radically different to those obtained from the last period. We infer that, in the most recent period, the mark-up of the German firms was reacting to changes in international competitiveness. Obviously, this finding agrees with the withdrawal of the vitamin $\mathrm{C}$ cartel.

\section{Acknowledgement}

Financial assistance from the Spanish Ministry of Science and Technology (SEJ200508764) and IVIE is gratefully acknowledged.

\section{References}

Box, G., \& Pierce, D. (1970). Distribution of residual autocorrelations in autoregressive moving average time series models. Journal of the American Statistical Association, 65, 1509-1526.

Bresnahan, T. F. (1989). Empirical studies of industries with market power. In R. Schmalensee \& R. Willing (Eds.), Handbook of industrial organization (pp. 1012-1057). Amsterdam: North-Holland.

Dornbusch, R. (1987). Exchange rates and prices. American Economic Review, 77, 93-106.

Gupta, S. (2001). The effect of bid rigging on prices: A study of the highway construction industry. Review of Industrial Organization, 19, 453-467.

Hung, W., Kim, Y., \& Ohno, K. (1993). Pricing exports: A cross-country study. Journal of International Money and Finance, 12, 3.

Kongsted, H. C. (1998). Modeling price and quantity relations for Danish manufacturing exports. Journal of Business and Economic Statistics, 16, 81-91.

Krugman, P. R. (1987). Pricing to market when the exchange rate changes. In S. W. Arndt \& J. D. Richardson (Eds.), Real financial linkages among open economies. Cambridge: MIT Press.

Ljung, G., \& Box, G. (1979). On a measure of lack of fit in time series models. Biometrika, 66, 265-270.

Parker, P. M., \& Röller, L. H. (1997). Collusive conduct in duopolies: Multimarket contact and cross-ownership in the mobile telephone industry. Rand Journal of Economics, 28(2), 304-322. 